\title{
BMJ Dabigatran use in Danish atrial Open fibrillation patients in 2011: a nationwide study
}

To cite: Sørensen $R$, Gislason G, Torp-Pedersen C, et al. Dabigatran use in Danish atrial fibrillation patients in 2011: a nationwide study. BMJ Open 2013:3:e002758 doi:10.1136/bmjopen-2013002758

- Prepublication history and additional material for this paper are available online. To view these files please visit the journal online (http://dx.doi.org/10.1136/ bmjopen-2013-002758).

GYHL and MLH contributed equally.

Received 19 February 2013

Revised 4 April 2013

Accepted 5 April 2013

This final article is available for use under the terms of the Creative Commons Attribution Non-Commercial 2.0 Licence; see http://bmjopen.bmi.com

For numbered affiliations see end of article.

Correspondence to Dr Rikke Sørensen; rs@heart.dk

Rikke Sørensen, ${ }^{1,2}$ Gunnar Gislason, ${ }^{1,3}$ Christian Torp-Pedersen, ${ }^{4}$ Jonas Bjerring Olesen, ${ }^{1}$ Emil L Fosbøl, ${ }^{5}$ Morten W Hvidtfeldt, ${ }^{1}$ Deniz Karasoy, ${ }^{1}$ Morten Lamberts, ${ }^{1}$ Mette Charlot, ${ }^{1,6}$ Lars Køber, ${ }^{5}$ Peter Weeke, ${ }^{1}$ Gregory Y H Lip, ${ }^{7}$ Morten Lock Hansen ${ }^{1}$

\section{ABSTRACT}

Objective: Dabigatran was recently approved for anticoagulation in patients with atrial fibrillation (AF); data regarding real-world use, comparative effectiveness and safety are sparse.

Design: Pharmacoepidemiological cohort study. Methods/settings: From nationwide registers, we identified patients with an in-hospital or outpatientclinic AF diagnosis who claimed a prescription of dabigatran 110 or $150 \mathrm{mg}$, or vitamin $\mathrm{K}$ antagonist (VKA), between 22 August and 31 December 2011. HRs of thromboembolic events (ischaemic stroke, transitory ischaemic attack and peripheral artery embolism) and bleedings were estimated using Cox regression analyses in all patients and stratified by previous VKA use.

Results: Overall, $1612(3.1 \%)$ and 1114 (2.1\%) patients claimed a prescription of dabigatran 110 and $150 \mathrm{mg}$, and $49640(94.8 \%)$ of VKA. Patients treated with dabigatran $150 \mathrm{mg}$ were younger with less comorbidity than those treated with dabigatran $110 \mathrm{mg}$ and VKA, as were VKA naïve patients compared with previous VKA users. Recommendations set by the European Medicine Agency (EMA) for dabigatran were met in $90.3 \%$ and $55.5 \%$ of patients treated with 110 and $150 \mathrm{mg}$. Patients treated with $150 \mathrm{mg}$ dabigatran, who did not fulfil the recommendations by EMA, were $>80$ years, patients with liver or kidney disease, patients with previous bleeding. Compared with VKA, the thromboembolic risk associated with dabigatran 110 and $150 \mathrm{mg}$ was HR 3.52 (1.40 to 8.84) and 5.79 (1.81 to 18.56) in previous VKA users, and HR $0.95(0.47$ to 1.91$)$ and $1.14(0.60$ to 2.16$)$ in VKA naïve patients. Bleeding risk was increased in previous VKA users receiving dabigatran $110 \mathrm{mg}$, but not in patients with $150 \mathrm{mg}$ dabigatran, nor in the VKA naïve users.

Conclusions: Deviations from the recommended use of dabigatran were frequent among patients treated with $150 \mathrm{mg}$. With cautious interpretation, dabigatran use in VKA naïve patients seems safe. Increased risk of thromboembolism and bleeding with dabigatran among previous VKA users was unexpected and may reflect patient selection and 'drug switching' practices.

\section{ARTICLE SUMMARY}

Article focus

- To describe dabigatran use in atrial fibrillation (AF) patients and compare it with vitamin $\mathrm{K}$ antagonist (VKA) use.

- To describe if dabigatran is prescribed according to the recommendations set by authorities.

- To estimate initial risk of thrombosis and bleedings related to dabigatran and VKA use among all patients, and stratified by previous use of VKA.

\section{Key messages}

- Dabigatran was prescribed in approximately $5 \%$ of AF patients with oral anticoagulation during the initial 4 months after approval.

- Recommendations set by the European Medicine Agency for dabigatran were met in $90.3 \%$ and $55.5 \%$ of patients treated with 110 and $150 \mathrm{mg}$, respectively.

- Compared with VKA, the thromboembolic risk associated with dabigatran 110 and $150 \mathrm{mg}$ was higher in previous VKA users, but comparable in VKA naive patients. Bleeding risk was increased in previous VKA users (D110 mg). Increased risk of thromboembolism and bleeding with dabigatran among previous VKA users may reflect patient selection and 'drug switching' practices.

Strengths and limitations of this study

- The main strength is the nationwide complete dataset of unselected AF patients and the use of validated pharmacoepidemiological methods.

- The main limitation is the short follow-up time.

\section{INTRODUCTION}

Stroke is a serious complication of atrial fibrillation $(\mathrm{AF})$, and prevention with antithrombotic medication has high priority. ${ }^{1} 2$ Until recently, vitamin $\mathrm{K}$ antagonists (VKA) have been the drug of first choice in highrisk patients with $\mathrm{AF}^{3}$ but food and drug interactions and the need for frequent 
monitoring within a narrow therapeutic range makes VKA unattractive to many patients. ${ }^{4}$

The novel oral anticoagulant dabigatran etexilate has been compared with VKA in patients with non-valvular $\mathrm{AF}$ in a large phase 3 randomised trial; it has been shown to be non-inferior to VKA with a comparable or lower risk of strokes, and with a more favourable sideeffect profile concerning serious bleedings. ${ }^{4}$ Dabigatran has fewer interactions with food and drugs than VKA and does not need monitoring of its anticoagulant effect. ${ }^{5}$ Moreover, dabigatran $150 \mathrm{mg}$ twice daily was superior to VKA in preventing stroke, with an additional overall reduction of cardiovascular mortality, and without increasing the risk of major bleeding. ${ }^{4}$ In patients with a clear indication for oral anticoagulation and without contraindications for therapy, the 2012 focused update of the European Society of Cardiology $\mathrm{AF}$ guidelines recommends one of the novel anticoagulants (dabigatran, rivaroxaban or apixaban) as a first-line choice of anticoagulation. ${ }^{2} 67$

Dabigatran was the first drug to be approved by the authorities for patients with non-valvular AF; however, the approval was followed by several concerns including case reports of serious bleedings ${ }^{8}{ }^{9}$ as well as concerns about poor adherence to therapy. ${ }^{10}$ Consequently, the Food and Drug Administration (FDA) in the USA, and European Medicine Agency (EMA) brought a safety announcement of serious bleedings. ${ }^{11}{ }^{12}$ EMA has approved the use of dabigatran in AF patients if one of the following risk factors are present: previous stroke, transient ischaemic attack, age $\geq 75$ years, left-ventricular ejection fraction $<40 \%$ or age $\geq 65$ years with one of the following: diabetes, coronary heart disease or hypertension. A dose of $150 \mathrm{mg}$ twice daily is recommended unless the patients are $\geq 80$ years, or with an increased risk of bleeding where a dose of $110 \mathrm{mg}$ twice daily is preferred/should be considered. ${ }^{2}$ The 2012 European Society of Cardiology guidelines on AF management state that dabigatran $150 \mathrm{mg}$ twice daily is the default dose, with the $110 \mathrm{mg}$ twice daily dose being recommended in those aged $\geq 80$ years, with high bleeding risk (HAS-BLED $\geq 3$ ) and concomitant interacting drugs (eg, verapamil). ${ }^{2}$

Until now, only preliminary real-life postapproval data have reported on the use of dabigatran. ${ }^{13-15}$ The purpose of this nationwide cohort study was to describe initial postapproval use, comparative effectiveness and safety of treatment with dabigatran 110 and $150 \mathrm{mg}$ twice daily among patients with AF, compared with those with VKA, during the initial 4 months after approval.

\section{METHODS}

\section{Data sources}

Nationwide administrative registers were linked on an individual level. For this study, we used: (1) The Danish National Patient Register, which holds information on all admissions to Danish hospitals since 1978 with one primary and, if appropriate, one or more secondary diagnoses coded according to the International Classification of Diseases (ICD) 8 and 10. (2) The National Prescription Register holds information on all prescriptions dispensed in Danish pharmacies since 1995 (coded according to the Anatomical Therapeutic Chemical (ATC) classification system), including information on the date of dispensation, strength and number of tablets dispensed. All pharmacies are required by Danish legislation to provide information that ensures complete and accurate registration. ${ }^{16}{ }^{17}$ (3) The Civil Register holds information of vital status of all citizens.

\section{Study population}

We identified all Danish residents registered with a diagnosis of AF (ICD-10 code I48) between 1 January 1995 and 31 December 2011 by the Danish National Patient Register (see online supplementary figure S1). All AF patients admitted to the hospital with AF, managed for $\mathrm{AF}$ in an outpatient clinic/ambulatory or seen at an emergency department contact for AF were eligible for the study.

\section{Warfarin and dabigatran therapy}

Patients with a prescription claim of VKA (ATC B01AA03) or dabigatran (ATC B01AE07) between 22 August and 31 December 2011 were included. According to their first prescription claim in this period, patients were stratified in three groups: VKA, dabigatran $110 \mathrm{mg}$ twice daily and dabigatran $150 \mathrm{mg}$ twice daily. Prescription claims of VKA from 0 to 180 days prior to baseline stratification were registered and classified as previous VKA therapy. Furthermore, patients were stratified according to previous use of VKA, since risk of bleeding can be higher in VKA naive patients than in previous VKA users. ${ }^{18} 19$ Use of VKA and dabigatran 110 and $150 \mathrm{mg}$ was included as dichotomous variables since the study period was short.

\section{Comobidities and concomitant medical therapy}

Comorbidities of congestive heart failure, hypertension, diabetes mellitus, thromboembolism (ischaemic stroke, transitory ischaemic attack and peripheral artery embolism), vascular disease (myocardial infarction, peripheral artery disease and aortic plaque) and previous bleeding within 180 days prior to index (22 August 2011) were determined, as performed in previous studies. ${ }^{20} 21$ Concomitant medical treatment with digoxin, amiodarone, Class 1C antiarrythmics, sotalol, $\beta$-blockers, nondihydropyridine calcium channel blockers, non-steroidal anti-inflammatory drugs and aspirin was assessed. Criteria for comorbidities, ICD-8 and ICD-10 diagnoses and ATC codes used in the analyses are listed in the online supplementary material, table 1 , and have been used in similar analyses previously. ${ }^{18}{ }^{20} \mathrm{CHADS}_{2}$ (congestive heart failure, hypertension, age $\geq 75$ years, diabetes mellitus, stroke/transient ischaemic attack), 
Table 1 Baseline characteristics

\begin{tabular}{|c|c|c|c|c|}
\hline Treatment group, N (\%) & Warfarin 2.5 mg & Dabigatran 110 mg & Dabigatran 150 mg & p Value \\
\hline \multicolumn{5}{|l|}{ Characteristics } \\
\hline Number of patients & 49640 & 1612 & 1114 & \\
\hline Age, mean (SD) (years) & $73.5( \pm 10.0)$ & $79.6( \pm 8.3)$ & $67.9( \pm 8.15)$ & \\
\hline Age $65-74$ years & $16800(33.8)$ & $278(17.3)$ & 594 (53.3) & $<0.001$ \\
\hline Age $\geq 75$ years & 24487 (49.3) & 1245 (77.2) & 225 (20.2) & $<0.001$ \\
\hline Female & 19380 (39.0) & $850(52.7)$ & $409(36.7)$ & $<0.001$ \\
\hline Male & $30280(61.0)$ & 762 (47.3) & 705 (63.3) & $<0.001$ \\
\hline \multicolumn{5}{|l|}{ Comorbidity } \\
\hline Heart failure & $8623(17.4)$ & $286(17.7)$ & $84(7.5)$ & $<0.001$ \\
\hline Hypertension & $27838(56.1)$ & $834(51.7)$ & $501(44.9)$ & $<0.001$ \\
\hline Diabetes mellitus & $8276(16.7)$ & $241(15.0)$ & $153(13.7)$ & 0.007 \\
\hline Previous thromboembolism & $3605(7.3)$ & $136(8.4)$ & $66(5.9)$ & 0.04 \\
\hline Vascular disease & $6928(14.0)$ & $265(16.4)$ & $113(10.1)$ & $<0.001$ \\
\hline Alcohol & $1723(3.5)$ & $61(3.8)$ & $50(4.5)$ & 0.15 \\
\hline Liver & $690(1.4)$ & $31(1.9)$ & $17(1.5)$ & 0.19 \\
\hline Kidney disease & $3341(6.7)$ & $96(6.0)$ & $36(3.2)$ & $<0.001$ \\
\hline Previous bleeding & $5171(10.4)$ & $209(13.0)$ & $78(7.0)$ & $<0.001$ \\
\hline Previous VKA use* & $45403(91.5)$ & $782(48.5)$ & 349 (31.3) & $<0.001$ \\
\hline No previous VKA use & $4237(8.5)$ & $830(51.5)$ & $765(68.7)$ & $<0.001$ \\
\hline \multicolumn{5}{|l|}{ Concomitant therapy } \\
\hline Digoxin & $17047(34.3)$ & $488(30.3)$ & 207 (18.6) & $<0.001$ \\
\hline Amiodarone & $2310(4.7)$ & $56(3.5)$ & $36(3.2)$ & 0.008 \\
\hline Class $1 \mathrm{C}$ AA & $979(2.0)$ & $19(1.2)$ & $31(2.8)$ & 0.01 \\
\hline Sotalol & $967(2.0)$ & $27(1.7)$ & $26(2.3)$ & 0.47 \\
\hline$\beta$-Blockers & $31133(62.7)$ & $808(50.1)$ & $554(49.7)$ & $<0.001$ \\
\hline Non-dihydropyridine CCBsł & $4215(8.5)$ & $163(10.1)$ & $56(5.0)$ & $<0.001$ \\
\hline NSAIDs & 7567 (15.2) & $298(18.5)$ & $236(21.2)$ & $<0.001$ \\
\hline Aspirin & $14853(29.9)$ & $658(40.8)$ & 435 (39.1) & $<0.001$ \\
\hline \multicolumn{5}{|l|}{$\mathrm{CHADS}_{2} \S$} \\
\hline Low (score 0) & $8761(17.7)$ & $141(8.8)$ & $421(37.8)$ & $<0.001$ \\
\hline Intermediate (score 1) & $17078(34.4)$ & $567(35.2)$ & 407 (36.5) & $<0.001$ \\
\hline High (score 2-6) & 23801 (48.0) & $904(56.0)$ & $286(25.7)$ & $<0.001$ \\
\hline Mean score (SD) & $1.5( \pm 1.1)$ & $1.8( \pm 1.1)$ & $1.0( \pm 1.0)$ & $<0.001$ \\
\hline \multicolumn{5}{|l|}{$\mathrm{CHA}_{2} \mathrm{DS}_{2}$-VASc } \\
\hline Low (score 0) & 2226 (4.5) & $24(1.5)$ & 99 (8.9) & $<0.001$ \\
\hline Intermediate (score 1) & 6405 (12.9) & $82(5.4)$ & $262(23.5)$ & $<0.001$ \\
\hline High (score 2-6) & 41009 (82.6) & $1506(93.4)$ & $753(67.6)$ & $<0.001$ \\
\hline Mean score (SD) & $2.9( \pm 1.5)$ & $3.4( \pm 1.4)$ & $2.2( \pm 1.3)$ & $<0.001$ \\
\hline \multicolumn{5}{|l|}{ HAS-BLED** } \\
\hline Low (score 0) & $15033(30.3)$ & $344(21.4)$ & 404 (36.3) & $<0.001$ \\
\hline Intermediate (score 1) & 18569 (37.4) & $626(38.8)$ & $418(37.5)$ & $<0.001$ \\
\hline High (score 2-6) & 16038 (32.3) & 642 (39.8) & $292(26.2)$ & $<0.001$ \\
\hline Mean score (SD) & $2.1( \pm 1.0)$ & $2.3( \pm 1.0)$ & $1.86( \pm 1.0)$ & $<0.001$ \\
\hline
\end{tabular}

*Previous VKA use: prescription claims of warfarin from 0 to 180 days prior to baseline stratification. †Class 1C AA:drug coded as ATC 'C01B'.

$\ddagger$ Non-dihydropyridine CCBs: drugs coded as 'C08DA'.

$\S \mathrm{CHADS}_{2}$ : congestive heart failure, hypertension, age $\geq 75$ years, diabetes mellitus, stroke/transient ischaemic attack.

$\prod_{1} \mathrm{CHA}_{2} \mathrm{DS}_{2}-\mathrm{VASc}$ : $\mathrm{CHADS}_{2}$, adding vascular disease, age 65-75 and female sex.

**HAS-BLED: hypertension, abnormal renal/liver function, stroke, bleeding history or predisposition, labile international normalised ratio(left out due to lack of information, as carried out previously), elderly ( $>65$ years), drugs/alcohol concomitantly.

NSAIDs, non-steroidal anti-inflammatory drugs; VKA, vitamin $\mathrm{K}$ antagonist.

$\mathrm{CHA}_{2} \mathrm{DS}_{2}-\mathrm{VASc}$ (ie, $\mathrm{CHADS}_{2}$ and adding vascular disease, age 65-75 and female sex) and HAS-BLED (hypertension, abnormal renal/liver function, stroke, bleeding history or predisposition, labile international normalised ratio(left out due to lack of information, as performed in previous studies), elderly (>65 years), drugs/alcohol concomitantly) scores were calculated.
Identification and validation of these scores in similar cohorts have been described previously. ${ }^{182122}$

\section{Prescription patterns}

Description of the patients prescribed dabigatran 110 and $150 \mathrm{mg}$ twice daily according to recommendations 
by EMA is presented, as are the baseline differences between previous VKA users and VKA naïve patients. ${ }^{2} 11$

\section{Endpoints: thromboembolism and bleeding}

The following two endpoints were assessed: (1) thromboembolism was defined as an admission with a thromboembolic diagnosis (including ischaemic stroke, transitory ischaemic attack and peripheral artery embolism). (2) Bleeding was defined as an admission with a bleeding diagnosis (including cerebral bleedings, bleedings from the respiratory tract, gastrointestinal bleedings and bleedings from the urinary tract). ICD-10 codes used to define the endpoints are listed in online supplementary table S1.

\section{Statistical analyses}

Baseline variables for patients on warfarin, dabigatran 110 or $150 \mathrm{mg}$ are presented, referring to the patients' first exposure group, as are the differences in baseline characteristics in previous VKA users and VKA naïve patients. Logistic regression analysis was used to determine variables associated with dabigatran use. Crude incidence rates per 100 person-years and adjusted HRs of thromboembolism and bleeding were assessed in all patients and in previous VKA users and VKA naïve patients. ${ }^{1819}$ Patients were considered at risk (exposed) from the first date claiming a prescription of warfarin or dabigatran during the study period between 22 August and 31 December 2011. The study period was chosen since the use of dabigatran was approved by 22 August 2011, and follow-up data obtained from the nationwide registries were only available until 31 December 2011. Patients were censored at the first thromboembolic or bleeding event, at death or at the end of the study period. Adjusted risks associated with dabigatran 110 and $150 \mathrm{mg}$ use were estimated using the Cox proportional-hazards models, with warfarin as reference. The analyses were adjusted for age-groups $(<65,65-74$ and $\geq 75$ ), sex, comorbidity and concomitant medical treatment. The models were tested for the absence of interactions, linearity of continuous variables and fulfilment of the proportional hazard assumption, and found to be valid. Calculations were carried out using the SAS statistical software V.9.2 (SAS Institute, Cary, North Carolina, USA). The study was conducted and reported in accordance with the Strengthening and the Reporting of Observational Studies in Epidemiology recommendations. ${ }^{23}$

\section{RESULTS}

\section{Prescription patterns}

Between 22 August and 31 December 2011, a total of $52366 \mathrm{AF}$ patients claimed a prescription for oral anticoagulation. Of these, $1612(3.1 \%)$ and $1114(2.1 \%)$ patients were treated with dabigatran 110 and $150 \mathrm{mg}$ twice daily, and $49640(94.8 \%)$ were treated with VKA. Compared with VKA and dabigatran $110 \mathrm{mg}$ twice daily, patients treated with dabigatran $150 \mathrm{mg}$ were younger with less comorbidity, as well as lower $\mathrm{CHA}_{2} \mathrm{DS}_{2} \mathrm{VASc}$ and HAS-BLED scores. Among dabigatran users, 782 $(48.5 \%)$ in the $110 \mathrm{mg}$ group and $349(31.3 \%)$ in the $150 \mathrm{mg}$ group had previously used VKA $(\mathrm{p}<0.001)$ Baseline characteristics are presented in table 1. Independent predictors of dabigatran use are presented in table 2. Of note, 171 patients (34 (2.1\%) and 137 $(12.3 \%)$ users of dabigatran 110 and $150 \mathrm{mg}$, respectively) were initiated on dabigatran without the presence of relevant risk factors, while 481 patients only had one 'moderate' risk factor (122 (7.6\%) and 137 (32.2\%) for dabigatran 110 and $150 \mathrm{mg})$.

\section{Compliance with European recommendations}

Among patients treated with dabigatran $110 \mathrm{mg}, 90.3 \%$ fulfilled the labelled recommendations listed by EMA; this applied to $55.5 \%$ among users of $150 \mathrm{mg}$. Details

Table 2 Predictors associated with dabigatran use, results from the logistic regression analysis

\begin{tabular}{|c|c|c|c|}
\hline & OR & $95 \% \mathrm{Cl}$ & p Value \\
\hline Male & 1.00 & & \\
\hline Female & 0.70 & (0.64 to 0.76$)$ & $<0.001$ \\
\hline Age $65-74$ & 1.14 & (0.96 to 1.36$)$ & 0.14 \\
\hline Age $\geq 75$ & 1.50 & (1.24 to 1.82$)$ & $<0.001$ \\
\hline Heart failure & 1.23 & (1.05 to 1.44$)$ & 0.01 \\
\hline Hypertension & 1.39 & (1.13 to 1.71$)$ & 0.002 \\
\hline Diabetes & 1.16 & (1.01 to 1.32$)$ & 0.03 \\
\hline Previous thromboembolism & 1.18 & (0.97 to 1.44$)$ & 0.11 \\
\hline Vascular disease & 1.02 & (0.91 to 1.16$)$ & 0.14 \\
\hline Previous bleeding & 1.10 & (0.94 to 1.30$)$ & 0.24 \\
\hline $\mathrm{CHADS}_{2}$ group$^{*}$ & 0.81 & (0.70 to 0.93$)$ & 0.003 \\
\hline $\mathrm{CHA}_{2} \mathrm{DS}_{2}-\mathrm{VASc}$ group $\dagger$ & 1.00 & (0.88 to 1.14$)$ & 0.98 \\
\hline HAS-BLED group $\ddagger$ & 1.03 & (0.89 to 1.19$)$ & 0.73 \\
\hline
\end{tabular}


Table 3 Indications and contraindication for dabigatran use

\begin{tabular}{|c|c|c|c|}
\hline & Dabigatran 110 mg & Dabigatran 150 mg & p Value \\
\hline \multicolumn{4}{|l|}{ Indications } \\
\hline \multicolumn{4}{|l|}{ One risk factor } \\
\hline Heart failure & $286(17.7)$ & $84(7.5)$ & $<0.001$ \\
\hline Previous thromboembolism & $136(8.4)$ & $66(5.9)$ & 0.01 \\
\hline Age $\geq 75$ years & 1245 (77.2) & $225(20.2)$ & $<0.001$ \\
\hline \multicolumn{4}{|l|}{ At least two risk factors } \\
\hline Hypertension & $834(51.7)$ & $501(44.9)$ & $<0.001$ \\
\hline Diabetes mellitus & $241(15.0)$ & $153(13.7)$ & 0.37 \\
\hline Vascular disease & $265(16.4)$ & $113(10.1)$ & $<0.001$ \\
\hline Age 65-74 years & $278(17.3)$ & $594(53.3)$ & $<0.001$ \\
\hline \multicolumn{4}{|l|}{ Risk factors } \\
\hline$\geq 1$ high* or $\geq 2$ moderate* & $1456(90.3)$ & $618(55.5)$ & $<0.001$ \\
\hline 1 Moderate* & $122(7.6)$ & $359(32.2)$ & $<0.001$ \\
\hline None & $34(2.1)$ & 137 (12.3) & $<0.001$ \\
\hline \multicolumn{4}{|l|}{ Contraindications } \\
\hline Liver & $31(1.9)$ & $17(1.5)$ & 0.44 \\
\hline Kidney disease & $96(6.0)$ & 36 (3.2) & 0.001 \\
\hline Previous bleeding & $209(13.0)$ & $78(7.0)$ & $<0.001$ \\
\hline Age $\geq 80$ & $953(59.1)$ & $42(3.8)$ & $<0.001$ \\
\hline
\end{tabular}

relating to recommended indications and contraindications are presented in table 3 .

\section{Thromboembolism and bleeding events}

Duration of follow-up was 4 months and 9 days. Event rates of thromboembolism and bleedings per 100 patient-years and number of events are shown in figure 1 (for all patients, and in VKA experienced and VKA naïve patients). Related adjusted HRs are shown in figure 2.

\section{VKA experienced versus VKA naive}

VKA experienced and VKA naive patients differed in baseline characteristics (table 4). Unexpectedly, among all patients, the adjusted risk of thromboembolism was higher among users of dabigatran compared with users of warfarin, but when stratified by previous VKA use, the increased risk of thromboembolism was only seen among previous VKA users (for both 110 and $150 \mathrm{mg}$ doses). Among all patients, the adjusted risk of bleeding was increased among users of dabigatran $110 \mathrm{mg}$ with warfarin as reference. Stratified by previous VKA use, this increased risk only persisted among VKA experienced patients.

\section{DISCUSSION}

This study describes the use of dabigatran and warfarin in a nationwide cohort of AF patients after approval of dabigatran. Our main findings were as follows: (1) dabigatran was prescribed in approximately $5 \%$ of patients with oral anticoagulation; (2) users of dabigatran $150 \mathrm{mg}$ twice daily were younger with less comorbidity
Figure 1 Event rates and crude incidence rates per 100 patient years.

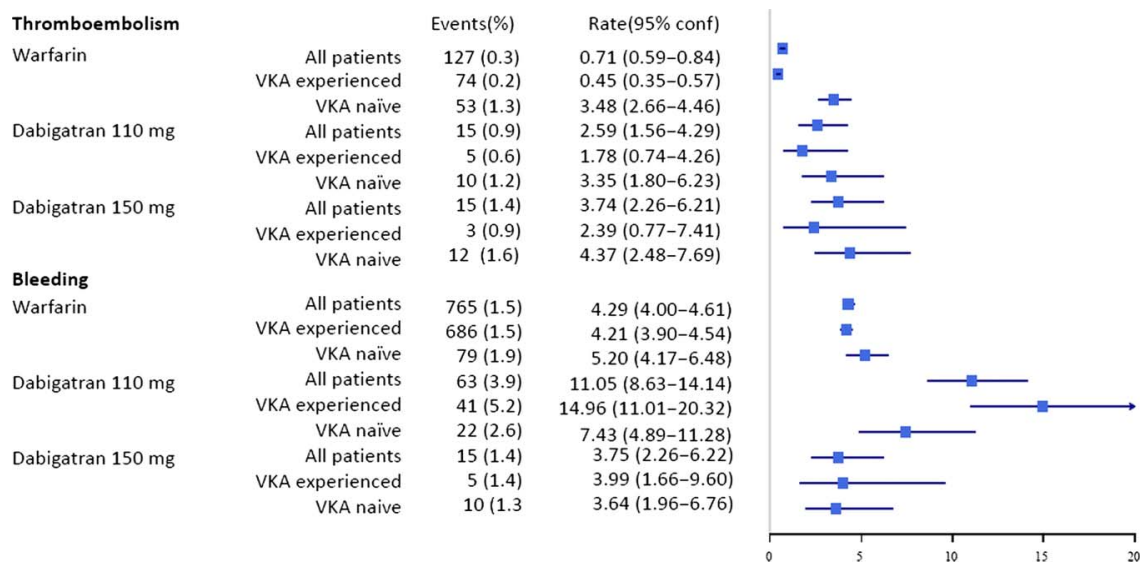


Figure 2 Adjusted risk of thromboembolic events and bleeding (Cox proportional hazard model).

$\begin{array}{lr}\begin{array}{l}\text { Thromboembolism } \\ \text { All patients }\end{array} & \begin{array}{r}\text { Warfarin } \\ \text { Dabigatran } 110 \mathrm{mg} \\ \text { Dabigatran } 150 \mathrm{mg} \\ \text { Warfarin }\end{array} \\ \text { VKA experienced } & \begin{array}{r}\text { Dabigatran } 110 \mathrm{mg} \\ \text { Dabigatran } 150 \mathrm{mg} \\ \text { Warfarin }\end{array} \\ \text { VKA naïve } & \begin{array}{r}\text { Dabigatran } 110 \mathrm{mg} \\ \text { Dabigatran } 150 \mathrm{mg}\end{array} \\ \text { Bleeding } & \text { Warfarin } \\ \text { All patients } & \begin{array}{r}\text { Dabigatran } 110 \mathrm{mg} \\ \text { Dabigatran } 150 \mathrm{mg} \\ \text { Warfarin }\end{array} \\ \text { VKA experienced } & \begin{array}{r}\text { Dabigatran } 110 \mathrm{mg} \\ \text { Dabigatran } 150 \mathrm{mg} \\ \text { Warfarin }\end{array} \\ \text { VKA naive } & \text { Dabigatran } 110 \mathrm{mg} \\ & \text { Dabigatran } 150 \mathrm{mg}\end{array}$

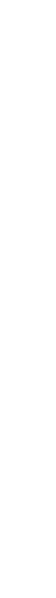

In the present study, few patients $\geq 80$ years were treated with $150 \mathrm{mg}$ dabigatran, compared with more than half of the patients on $110 \mathrm{mg}$ dabigatran. This is reassurring as there is an increased risk of bleeding among older patients; thus, $110 \mathrm{mg}$ dabigatran is being recommended in those aged $>80$ years. ${ }^{425}$ In addition, we found that one-fourth of the patients treated with dabigtran $150 \mathrm{mg}$ had a high bleeding risk (as reflected by HAS-BLED score $\geq 2$ ), and some were diagnosed with liver or renal disease. In those at high bleeding risk, $110 \mathrm{mg}$ twice daily is recommended. ${ }^{26}$

\section{Thromboembolism and bleedings, with or without previous VKA use}

The duration of follow-up was approximately 4 months, since the registry data were only available for the period until the end of 2011. In the overall cohort, we unexpectedly found that the adjusted risk of thromboembolic events was increased among users of both doses of dabigatran. ${ }^{4}$ Among VKA naive subjects, the risk of thromboembolic events was comparable with VKA with both doses of dabigatran, but increased in dabigatran users who had previously used VKA. This is in contrast to results from the RE-LY study, where thromboembolic events among previous VKA users and VKA naive patients were similar between groups. ${ }^{27}$ The interpretation of this is that dabigatran, at least at this point, is being used in clinical settings where VKA have failed. Notably, these results reflect real-life clinical use of a novel anticoagulant that is not necessary but is in accordance with use in a controlled clinical trial. Guidelines recommend a novel oral anticoagulant if warfarin is difficult to keep within therapeutic range, in case of side-effects, or an inability to undertake international normalised ratio (INR) monitoring (class IB). ${ }^{2}$ The increased thromboembolic risk in previous VKA users prescribed that dabigatran users can plausibly be explained by several unmeasured confounders including poor compliance or unmeasured serious comorbidities. Differences in baseline characteristics between VKA 
Table 4 Baseline differences between VKA naive and VKA experienced

\begin{tabular}{|c|c|c|c|}
\hline Treatment group, N (\%) & VKA naive & VKA experienced* & p Value \\
\hline \multicolumn{4}{|l|}{ Characteristics } \\
\hline Number of patients & 5832 & 46534 & \\
\hline Age, mean (SD), years & $72.2( \pm 10.9)$ & $73.8( \pm 9.9)$ & \\
\hline Age $65-74$ years & 2003 (34.3) & 15669 (33.7) & 0.30 \\
\hline Age $\geq 75$ years & $2583(44.3)$ & $23374(50.2)$ & $<0.001$ \\
\hline Female & $2471(42.4)$ & $18168(39.0)$ & $<0.001$ \\
\hline Male & $3361(57.6)$ & $28366(60.9)$ & $<0.001$ \\
\hline \multicolumn{4}{|l|}{ Comorbidity } \\
\hline Heart failure & $616(10.6)$ & $8377(18.0)$ & $<0.001$ \\
\hline Hypertension & $2422(41.5)$ & 26751 (57.5) & $<0.001$ \\
\hline Diabetes mellitus & 776 (13.3) & 7894 (17.0) & $<0.001$ \\
\hline Previous thromboembolism & $351(6.0)$ & $3456(7.4)$ & $<0.001$ \\
\hline Vascular disease & 809 (13.9) & $6497(14.0)$ & 0.85 \\
\hline Alcohol & $236(4.1)$ & $1598(3.4)$ & 0.02 \\
\hline Liver & $94(1.6)$ & $644(1.4)$ & 0.16 \\
\hline Kidney disease & $353(6.0)$ & $3120(6.7)$ & 0.06 \\
\hline Previous bleeding & 492 (8.4) & 4966 (10.7) & $<0.001$ \\
\hline Warfarin & $4237(72.7)$ & 45403 (97.6) & $<0.001$ \\
\hline Dabigatran 110 mg & 830 (14.2) & $782(1.7)$ & $<0.001$ \\
\hline Dabigatran 150 mg & $765(13.1)$ & $349(0.8)$ & $<0.001$ \\
\hline \multicolumn{4}{|l|}{ Concomitant therapy } \\
\hline Digoxin & 808 (13.9) & $16934(36.4)$ & $<0.001$ \\
\hline Amiodarone & $158(2.7)$ & $2244(4.8)$ & $<0.001$ \\
\hline Class $1 \mathrm{C} \mathrm{AA \dagger}$ & $88(1.5)$ & $941(2.0)$ & 0.008 \\
\hline Sotalol & $118(2.0)$ & 902 (1.9) & 0.66 \\
\hline$\beta$-Blockers & 2499 (42.9) & $29996(64.5)$ & $<0.001$ \\
\hline Non-dihydropyridine CCBsł & $1604(27.5)$ & $14436(31.0)$ & $<0.001$ \\
\hline NSAIDs & $1172(20.1)$ & $6929(14.9)$ & $<0.001$ \\
\hline Aspirin & 2517 (43.2) & $13429(28.9)$ & $<0.001$ \\
\hline \multicolumn{4}{|l|}{$\mathrm{CHADS}_{2} \S$} \\
\hline Low (score 0) & $1713(29.4)$ & $7610(16.4)$ & $<0.001$ \\
\hline Intermediate (score 1) & $2081(35.7)$ & $15971(34.3)$ & $<0.001$ \\
\hline High (score 2-6) & $2038(35.0)$ & 22953 (49.3) & $<0.001$ \\
\hline Mean score (SD) & $1.2( \pm 1.1)$ & $1.6( \pm 1.1)$ & \\
\hline \multicolumn{4}{|l|}{$\mathrm{CHA}_{2} \mathrm{DS}_{2}$-VASc- } \\
\hline Low (score 0) & $500(8.6)$ & $1849(4.0)$ & $<0.001$ \\
\hline Intermediate (score 1) & 991 (17.0) & $5758(12.4)$ & $<0.001$ \\
\hline High (score 2-6) & $4341(74.4)$ & 38927 (83.7) & $<0.001$ \\
\hline Mean score (SD) & $2.6( \pm 1.5)$ & $2.9( \pm 1.5)$ & \\
\hline \multicolumn{4}{|l|}{ HAS-BLED** } \\
\hline Low (score 0) & 1997 (34.2) & $13784(29.6)$ & $<0.001$ \\
\hline Intermediate (score 1) & $1994(34.1)$ & $17619(37.9)$ & $<0.001$ \\
\hline High (score 2-6) & $1841(31.6)$ & $15131(32.5)$ & $<0.001$ \\
\hline Mean score (SD) & $2.0( \pm 1.1)$ & $2.1( \pm 1.0)$ & \\
\hline
\end{tabular}

"Previous VKA use/VKA experienced: Prescription claims of warfarin from 0 to 180 days prior to baseline stratification.

†Class 1C AA:drug coded as ATC 'C01B'.

$\ddagger$ Non-dihydropyridine CCBs: drugs coded as 'C08DA'.

$\S \mathrm{CHAS}_{2}$ : Congestive heart failure, Hypertension, Age $\geq 75$ years, Diabetes mellitus, Stroke/transient ischaemic attack.

ๆ $\mathrm{CHA}_{2} \mathrm{DS}_{2}-$ VASc: $\mathrm{CHADS}_{2}$, adding vascular disease, age 65-75 and female sex.

${ }_{* \star}$ HAS-BLED: hypertension, abnormal renal/liver function, stroke, bleeding history or predisposition, labile international normalised ratio(left out due to lack of information, as carried out previously), elderly (>65 years), drugs/alcohol concomitantly.

NSAIDs, non-steroidal anti-inflammatory drugs; VKA, vitamin K antagonist.

naive and previous VKA users, the latter being associated with more comorbidities, support this assumption.

Broadly comparable patterns were seen concerning bleeding, with an increased risk among previous VKA users treated with dabigatran $110 \mathrm{mg}$, and a similar risk to warfarin among VKA naive patients with dabigatran.
These findings are somewhat surprising, given that VKA naïve patients usually have more bleedings shortly after initiation, at least in some studies ${ }^{18} 1927$ On the other hand, our finding supports current recommendations that patients complying with VKA treatment who are kept within the recommended therapeutic INR range 
(ie, with high time in therapeutic range) should remain on warfarin treatment rather than 'switch'. As patients treated with dabigatran $110 \mathrm{mg}$ twice daily in our study were older, with more comobidity and a higher HAS-BLED score (with increased bleeding risk), this could be a product of unmeasured confounders. ${ }^{25}$ Patients treated with dabigatran $110 \mathrm{mg}$ twice daily had higher $\mathrm{CHA}_{2} \mathrm{DS}_{2}$-VASc and HAS-BLED scores than patients treated with dabigatran $150 \mathrm{mg}$ twice daily, as did previous VKA users compared with VKA naive patients. One previous study showed that patients with both high $\mathrm{CHA}_{2} \mathrm{DS}_{2}$-VASc and HAS-BLED scores had the most net-clinical benefit from VKA treatment. ${ }^{22}$ Whether the high-risk patients in our study would have shown a net-clinical benefit from $150 \mathrm{mg}$ twice daily instead of $110 \mathrm{mg}$ dabigatran cannot be concluded from the present analyses. However, it is possible that clinicians may have opted to particularly use dabigatran $110 \mathrm{mg}$ twice daily in patients perceived to be at high risk for bleeding (ie, high HAS-BLED score) as the primary consideration, and given that stroke and bleeding risk parallel each other, the $\mathrm{CHA}_{2} \mathrm{DS}_{2}$-VASc score was correspondingly higher.

With cautious interpretation due to the low number of events and short follow-up, dabigatran use in VKA naive patients seems to be a safe option in our study without an increased risk of thromboembolic or bleeding events. ${ }^{27}$ In addition, our results call for a more cautious approach when shifting high-risk patients from VKA to dabigatran treatment.

\section{Strengths and limitations}

The strength of this study is the completeness of data, with a nationwide unselected cohort of $\mathrm{AF}$ patients initiated on oral anticoagulation. In Denmark, all citizens regardless of socioeconomic status, healthcare-insurance and geography are covered by a public healthcare system ensuring complete registration of outpatient contacts and hospital admissions. The pharmacies also register all claimed prescriptions. By the use of a unique personal registration number, administrative registers can be linked on an individual level. In this setting, it is possible to describe the initial Danish experience with dabigatran, compared with VKA, and indirectly reveal the doctors' interpretation of EMA's recommendations for dabigatran use in clinical practice. The register data used have been validated previously, ${ }^{16}{ }^{17} 28-30$ as have the methods used for assessment of comorbidity and risk stratification in patients with $\mathrm{AF}^{18}$ 20-22

One limitation is that we had no information of INR values, time in therapeutic range or creatine clearance. To overcome this drawback, methods from previous studies were used. $^{22}$ In the adjusted analyses, we included known confounders present in our registries, but unmeasured confounders may still have influenced our results. Another major limitation is the short period of follow-up, and thus the low number of events of both thromboembolism and bleeding. Thus, interpretations of these risks should be cautious and seen in the context of an early pattern after approval of dabigatran. In addition, our definition of bleeding varies from the definition used in the RE-LY trial, ${ }^{4}$ but at least it includes serious bleedings leading to hospitalisation, as has been used previously. ${ }^{18}$

\section{CONCLUSION}

Deviations from the recommended use of dabigatran were frequent among patients treated with $150 \mathrm{mg}$ twice daily. Dabigatran use in VKA naive patients with AF seems safe. Reasons for the increased risk of thromboembolic events with dabigatran (and bleeding with $110 \mathrm{mg}$ twice daily) among previous VKA users may reflect patient selection and 'drug switching' practices that merit a more cautious approach when shifting highrisk patients from VKA to dabigatran treatment. Additional real-life follow-up data of dabigatran use are warranted in the future.

Author affiliations

${ }^{1}$ Department of Cardiology, Copenhagen University Hospital Gentofte, Hellerup, Denmark

${ }^{2}$ Department of Cardiology, Copenhagen University Hospital Bispebjerg, Copenhagen, Denmark

${ }^{3}$ National Institute of Public Health, University of Southern Denmark, Copenhagen, Denmark

${ }^{4}$ Department of Cardiology, Aalborg University, Aalborg Hospital, Aalborg, Denmark

${ }^{5}$ Department of Cardiology, Copenhagen University Hospital Rigshospitalet, Copenhagen, Denmark

${ }^{6}$ Department of Cardiology, Copenhagen University Hospital Hillerød, Hillerød, Denmark

${ }^{7}$ University of Birmingham Centre for Cardiovascular Sciences, City Hospital, Birmingham, UK

Contributors MLH, GG, CT-P and RS participated in the study design and data analysis. RS wrote the paper. All authors interpreted the results, revised the report and approved the final version.

Funding The present study did not receive specific funding. GG is supported by an independent research scholarship from the Novo Nordisk Foundation.

\section{Competing interests None.}

Ethics approval Register studies do not require ethical approval in Denmark. The study was approved by the Danish Data Protection Agency (ref: 2007-41-1667).

Provenance and peer review Not commissioned; externally peer reviewed.

Data sharing statement No additional data are available.

\section{REFERENCES}

1. Camm AJ, Kirchhof P, Lip GY, et al. Guidelines for the management of atrial fibrillation: the task force for the management of atrial fibrillation of the European Society of Cardiology (ESC). Europace 2010;12:1360-420.

2. Camm AJ, Lip GY, De Caterina R, et al. 2012 focused update of the ESC Guidelines for the management of atrial fibrillation: an update of the 2010 ESC Guidelines for the management of atrial fibrillation. Developed with the special contribution of the European Heart Rhythm Association. Eur Heart J 2012;33:2719-47.

3. Hart RG, Pearce LA, Aguilar MI. Meta-analysis: antithrombotic therapy to prevent stroke in patients who have non-valvular atrial fibrillation. Ann Intern Med 2007;146:857-67.

4. Connolly SJ, Ezekowitz MD, Yusuf S, et al. Dabigatran versus warfarin in patients with atrial fibrillation. $N$ Engl $J$ Med 2009;361:1139-51. 
5. Blech S, Ebner T, Ludwig-Schwellinger E, et al. The metabolism and disposition of the oral direct thrombin inhibitor, dabigatran, in humans. Drug Metab Dispos 2008;36:386-99.

6. Granger CB, Alexander JH, McMurray JJ, et al. Apixaban versus warfarin in patients with atrial fibrillation. $N$ Engl $J$ Med 2011;365:981-92.

7. Patel MR, Mahaffey KW, Garg J, et al. Rivaroxaban versus warfarin in non-valvular atrial fibrillation. N Engl J Med 2011;365:883-91.

8. Garber ST, Sivakumar W, Schmidt RH. Neurosurgical complications of direct thrombin inhibitors-catastrophic hemorrhage after mild traumatic brain injury in a patient receiving dabigatran. $J$ Neurosurg 2012;116:1093-6.

9. Kernan L, Ito $S$, Shirazi $F$, et al. Fatal gastrointestinal hemorrhage after a single dose of dabigatran. Clin Toxicol 2012;50:571-3.

10. Salmela B, Joutsi-Korhonen L, Armstrong E, et al. Active online assessment of patients using new oral anticoagulants: bleeding risk, compliance, and coagulation analysis. Semin Thromb Hemost 2012;38:23-30.

11. Agency EM. 2012. http://www.ema.europa.eu/docs/en_GB/ document_library/Medicine_QA/2012/05/WC500127768.pdf

12. FDA. 2012. http://www.fda.gov/Drugs/ GuidanceComplianceRegulatoryInformation/Surveillance/ AdverseDrugEffects/ucm281856.htm

13. Leach MC, Anne P. Spencer. real-life dabigatran patient selection: change over time and compared to the RE-LY Study Population. 2012. http://www.abstractsonline.com/Plan/ViewAbstract.aspx? sKey=08fe $71 \mathrm{bf}-2580-4 \mathrm{cfe}-9281-\mathrm{a} 2 \mathrm{dcd} 4 \mathrm{ab} 9 \mathrm{aff} \& \mathrm{cKey}=67 \mathrm{df} 76 \mathrm{bc}-$ ec22-442d-9f66-b4d5e866d87a\&mKey=\%7b14145D5B-F96B-43548237-8F0937744BA4\%7d

14. Thelus R, Villines TC, Coster TS. Dabigatran versus warfarin among patients with atrial fibrillation: Real-world post-market results. 2012. http://www.abstractsonline.com/Plan/ViewAbstract.aspx? sKey=4911 efc8-20d6-42ba-a562-4087d52e57e4\&cKey=3972b1a9f575-449b-a713-2a45b15fca04\&mKey=\%7b14145D5B-F96B-43548237-8F0937744BA4\%7d

15. Charland SL, Malone DC, Agatep BC, et al. Real-world risk of thromboembolism or bleeding with warfarin or dabigatran therapy in patients with atrial fibrillation. 2012. http://www.abstractsonline.com/ Plan/ViewAbstract.aspx?sKey=a0bb3efd-f070-4c37-81c3Oee0ede4c5a4\&cKey=b91dba5f-391f-4f6c-a86dbc17b62b3299\&mKey=\%7b14145D5B-F96B-4354-82378F0937744BA4\%7d

16. Gaist D, Sorensen HT, Hallas J. The Danish prescription registries. Danish Med Bull 1997:44:445-8.

17. Gaist $\mathrm{D}$, Andersen $\mathrm{M}$, Aarup $\mathrm{AL}$, et al. Use of sumatriptan in Denmark in 1994-5: an epidemiological analysis of nationwide prescription data. Br J Clin Pharmacol 1997;43:429-33.
18. Hansen ML, Sorensen R, Clausen MT, et al. Risk of bleeding with single, dual, or triple therapy with warfarin, aspirin, and clopidogrel in patients with atrial fibrillation. Arch Intern Med 2010;170:1433-41.

19. Hylek EM, Evans-Molina C, Shea C, et al. Major hemorrhage and tolerability of warfarin in the first year of therapy among elderly patients with atrial fibrillation. Circulation 2007:115:2689-96.

20. Andersson C, Norgaard ML, Hansen PR, et al. Heart failure severity, as determined by loop diuretic dosages, predicts the risk of developing diabetes after myocardial infarction: a nationwide cohort study. Eur J Heart Fail 2010;12:1333-8.

21. Olesen JB, Lip GY, Hansen ML, et al. Validation of risk stratification schemes for predicting stroke and thromboembolism in patients with atrial fibrillation: nationwide cohort study. BMJ 2011;342:d124.

22. Olesen JB, Lip GY, Lindhardsen J, et al. Risks of thromboembolism and bleeding with thromboprophylaxis in patients with atrial fibrillation: a net clinical benefit analysis using a 'real world' nationwide cohort study. Thromb Haemost 2011;106:739-49.

23. von Elm E, Altman DG, Egger M, et al. The Strengthening the Reporting of Observational Studies in Epidemiology (STROBE) statement: guidelines for reporting observational studies. Lancet 2007;370:1453-7.

24. Kirley K, Qato DM, Kornfield R, et al. National trends in oral anticoagulant use in the United States, 2007 to 2011. Circ Cardiovasc Qual Outcomes 2012;5:615-21.

25. Eikelboom JW, Wallentin L, Connolly SJ, et al. Risk of bleeding with 2 doses of dabigatran compared with warfarin in older and younger patients with atrial fibrillation: an analysis of the randomized evaluation of long-term anticoagulant therapy (RE-LY) trial. Circulation 2011;123:2363-72.

26. Liesenfeld KH, Lehr T, Dansirikul C, et al. Population pharmacokinetic analysis of the oral thrombin inhibitor dabigatran etexilate in patients with non-valvular atrial fibrillation from the RE-LY trial. J Thromb Haemost 2011:9:2168-75.

27. Ezekowitz MD, Wallentin L, Connolly SJ, et al. Dabigatran and warfarin in vitamin $\mathrm{K}$ antagonist-naive and experienced cohorts with atrial fibrillation. Circulation 2010;122:2246-53.

28. Nickelsen TN. [Data validity and coverage in the Danish National Health Registry. A literature review]. Ugeskr Laeger 2001;164:33-7.

29. Hommel K, Rasmussen S, Madsen M, et al. The Danish Registry on Regular Dialysis and Transplantation: completeness and validity of incident patient registration. Nephrol Dial Transplant 2010;25:947-51.

30. Frost L, Vukelic Andersen L, Vestergaard $P$, et al. Trends in risk of stroke in patients with a hospital diagnosis of non-valvular atria fibrillation: National Cohort Study in Denmark, 1980-2002. Neuroepidemiology 2006;26:212-19. 